\title{
Genetic Structure of Field Populations of Begomoviruses and of Their Vector Bemisia tabaci in Pakistan
}

\author{
Belén Simón, José Luis Cenis, Francisco Beitia, Saif Khalid, \\ Ignacio M. Moreno, Aurora Fraile, and Fernando García-Arenal
}

First and second authors: Centro de Investigación y Desarrollo Agroalimentario, 30150 La Alberca (Murcia), Spain; third author: Departamento de Protección Vegetal, CIT-INIA, Carretera de La Coruña Km.7,5, 28040 Madrid, Spain; fourth author: Institute of Crop and Environmental Protection, Crop Diseases Research Programme, National Agricultural Research Centre, Islamabad 45500, Pakistan; and fifth, sixth, and seventh authors: Departamento de Biotecnología, ETS Ingenieros Agrónomos, 28040-Madrid, Spain. Accepted for publication 20 June 2003.

\begin{abstract}
Simón, B., Cenis, J. L., Beitia, F., Khalid, S., Moreno, I. M., Fraile, A., and García-Arenal, F. 2003. Genetic structure of field populations of begomoviruses and of their vector Bemisia tabaci in Pakistan. Phytopathology 93:1422-1429.

The genetic structure of field populations of begomoviruses and their whitefly vector Bemisia tabaci in Pakistan was analyzed. Begomoviruses and $B$. tabaci populations were sampled from different crops and weeds in different locations in Punjab and Sindh provinces, in areas where cotton leaf curl disease (CLCuD) occurs or does not occur. Phylogenetic analysis based on nucleotide sequences of the intergenic region in the viral DNA-A provided evidence of two clusters of isolates: viruses isolated from species in the family Malvaceae, and viruses isolated from other dicotyledon families. Analysis of the capsid protein (CP) open

reading frame grouped isolates into three geographical clusters, corresponding to isolates collected in Punjab, Sindh, or both provinces. Random amplified polymorphic DNA analyses of the B. tabaci population showed that intrapopulation diversity was high at both the local and regional scales. Sequence analysis of the mitocondrial cytochrome oxydase I (mt COI) gene showed that the $B$. tabaci population was structured into at least three genetic lineages corresponding to the previously described Indian, Southeast Asian, and Mediterranean-African clades. The Indian clade was present only in Punjab, the Mediterranean-African only in Sindh, and the Southeast Asian in both provinces. B. tabaci haplotypes of the Indian clade were found only in the Punjab, where CLCuD occurs. Hence, the geographical distribution of virus and vector genotypes may be correlated, because similar phylogenetic relationships were detected for the viral $\mathrm{CP}$ and the vector $\mathrm{mt}$ COI genes.
\end{abstract}

The emergence of new diseases caused by begomoviruses has been associated with changes in the incidence, the area of distribution $(6,8-10,47)$, and the genetic structure $(7,35,48)$ of the populations of their whitefly vector, Bemisia tabaci (Gennadius). In addition, a number of new recombinant Begomovirus spp. have been associated with outbreaks of a number of diseases $(44,45,50,53,54)$. Because the fate of a new genetic variant in the virus population may depend on different selection pressures, it is important to understand the factors involved in the evolution of begomoviruses to explain the emergence of new diseases caused by them $(28,38)$. The characterization of the genetic structure of the population of an organism may provide information important to understand its evolution. For vector-transmitted viruses, it would be desirable to have information on the genetic variability and structure of both the vector and virus population.

An important example of an emerging plant disease is cotton leaf curl disease (CLCuD), which has become the main threat to cotton production in Pakistan since it was first reported in the Punjab province in 1967 (1,24). CLCuD has severely affected more than 1 million ha in the Punjab province, and in the north of the Sindh province. Interestingly, CLCuD did not occur in most of the cotton-growing areas in Sindh until very recently (Fig. 1). A Begomovirus sp., Cotton leaf curl virus (CLCuV), recently reclassified as a group of different species (Cotton leaf curl Alabad virus [CLCuAV], Cotton leaf curl Kokhran virus [CLCuKV], and

Corresponding author: F. García-Arenal; E-mail address: fga@bit.etsia.upm.es

Publication no. P-2003-0917-01R

(C) 2003 The American Phytopathological Society
Cotton leaf curl Multan virus [CLCuMV] (17), has been associated consistently with CLCuD-affected plants $(5,55)$. For these viruses, only a DNA-A, but not a DNA-B, component has been identified $(5,36)$. $\mathrm{CLCuV}$ is a helper virus for a satellite-like DNA (DNA $\beta$ ), and infection by both CLCuV and DNA $\beta$ is necessary to cause the symptoms of CLCuD (4). DNA $\beta$ is encapsidated in $\mathrm{CLCuV}$ particles and, presumably, also is transmitted by $B$. tabaci (4). Mixed infections between CLCuV species, and recombinants among them, have been described from diseased cotton and other malvaceous and nonmalvaceous species in cotton-growing areas of Pakistan $(49,50,55)$.

B. tabaci can be thought of as a species complex containing numerous genetic and biological variants $(2,7,8,10,46)$. This variability is manifest by numerous variants, which have been recognized using several different genetic markers $(12,14,16,20,22)$. Sequence data of the mitochondrial cytochrome oxidase I gene (mt COI) has revealed that the analyzed B. tabaci populations from different locations worldwide are distributed in at least six well-supported lineages or clades that are strongly correlated with specific geographic areas on the continental scale $(7,18,33,34)$. Although slightly less informative, the analysis of the sequence of the internal transcribed spacer 1 (ITS1) region of rDNA produces a phylogeny consistent with that derived from mt COI (16). Previous studies have shown the presence, in Pakistan, of a $\mathrm{B}$. tabaci biotype not reported elsewhere, type $K$ (2). Hameed et al. (25) reported the presence in Pakistan of the B biotype. Finally, the analysis of $\mathrm{mt}$ COI sequences of samples from three $B$. tabaci populations collected in Pakistan from cotton (7) showed them to belong to two different phylogeographical groups, the Indian and Southeast Asia clades. This indicates a high variability of $B$. tabaci in Pakistan. 
Here, we report on an analysis of the genetic structure of $B$. tabaci populations in cotton-growing areas of Pakistan, and compare it with a genetic analysis of the Begomovirus population.

\section{MATERIALS AND METHODS}

Virus isolates and $\boldsymbol{B}$. tabaci populations. Cotton and other dicotyledonous crops and weeds showing Begomovirus-like symptoms (mainly leaf curl, vein thickening and enation, yellow vein, and mosaic) were sampled in a north-south transect of the cottongrowing area in the provinces of Punjab and Sindh, in Pakistan, in the locations indicated in Figure 1A. Samples were collected in autumn 1995 and spring 1997. Here, we define a virus isolate as the geminiviral DNA polymerase chain reaction (PCR) amplified from an individual plant. The analyses in this work also include isolates from samples collected in the Punjab province in 1996 by D. J. Robinson, Dundee, UK (isolates oymv201, clc62, and clc804 in Table 1) (55). B. tabaci adults were sampled in the same area, in the locations indicated in Figure 1B, in spring and fall 1997 and in spring 1998. Here, we define a population of $B$. tabaci as the set of whitefly individuals $(\approx 100$ adults) collected at a certain location in a single field. One whitefly population, sampled in Multan before 1995 and maintained at the SCRI, Dundee, UK (population PK4); a population sampled in Multan in 1995 and maintained in the NARC, Islamabad ( $\mathrm{Pj} 95.1)$; and the laboratory populations of biotype $\mathrm{B}$, collected in Almería (Spain) and biotype $\mathrm{K}$, collected in Pakistan $(2,22)$, also were included in some of the analyses. Begomovirus isolates and whitefly populations are shown in Tables 1 and 2, respectively, which include information on their origin.

Characterization and analyses of Begomovirus isolates. DNA purification from plant samples, primers for PCR amplification of begomoviral DNA, PCR procedures, and nucleotide sequence determination of PCR-amplified fragments have been described $(27,49)$. Two genomic regions were PCR amplified. For the first one, including the intergenic region (IR), primers were annealed to nucleotides 316 to 298 and 2,309 to 2,339, yielding a predicted fragment of $\approx 710$ nucleotides (nt). For the second region, including most of the capsid protein $(\mathrm{CP})$, primers were annealed to nucleotides 990 to 972 and 199 to 218, yielding a predicted fragment of $\approx 745 \mathrm{nt}$ (nucleotide numbering for primer positions according to sequence of CLCuMV, accession no. AJ002459). Although the nucleotide sequence of the primers was based on that of DNA-A of CLCuV-a (an isolate of CLCuMV) (17), as reported by Nadeem (40), they directed the amplification of DNA fragments from other Begomovirus spp. $(49,50)$.

Except for the CP open reading frame (ORF) of isolate p12 and the IR of a second variant from sample p26 (isolate p26b), sequences analyzed in this work have been previously reported $(49,50,55)$. Accession numbers in the EMBL data bank for all sequences are indicated in Table 1. DNA sequences were aligned by the program CLUSTALW (52) and genetic distances were estimated by Kimura's two-parameter method (32). Phylogenetic analyses were done using the neighbor-joining and maximum likelihood methods using the PHYLIP Package (version 3.6; J. Felsenstein, Seattle, WA).

Characterization and analyses of $B$. tabaci populations. Two different approaches were used for the genetic characterization of B. tabaci populations. First, random amplified polymorphic DNA (RAPD)-PCR analysis was applied to evaluate the intrapopulational genetic diversity of $13 \mathrm{~B}$. tabaci populations. Nine males were analyzed individually from each of 13 populations (total of 117 insects). Three populations were from the Punjab ( $\mathrm{Pj} 98.5, \mathrm{Pj}$ 98.8, and $\mathrm{Pj}$ 98.9), six were from Sindh (Sd 97.1, Sd 97.2, Sd 97.3, Sd 97.4, Sd 98.2, and Sd 98.6), two were the laboratory populations PK4 and Pj 95.1, and two were reference populations of biotypes B and K. RAPD-PCR analyses also were done on 24 individual male whiteflies from the populations collected in 1997 and 1998 (Table 2). Of these male whiteflies, 12 were randomly sampled from the Punjab populations and 12 from those from Sindh. DNA from individual insects was extracted in $200 \mathrm{mM}$ Tris- $\mathrm{HCl}, \mathrm{pH} 8.5,250 \mathrm{mM} \mathrm{NaCl}, 25 \mathrm{mM}$ EDTA, and $0.5 \%$ sodium dodecyl sulfate and precipitated with one volume of isopropanol (11), and RAPD-PCR amplification was performed according to a procedure previously described (22). Six 10-mer primers were selected based on preliminary experiments and used in PCR:
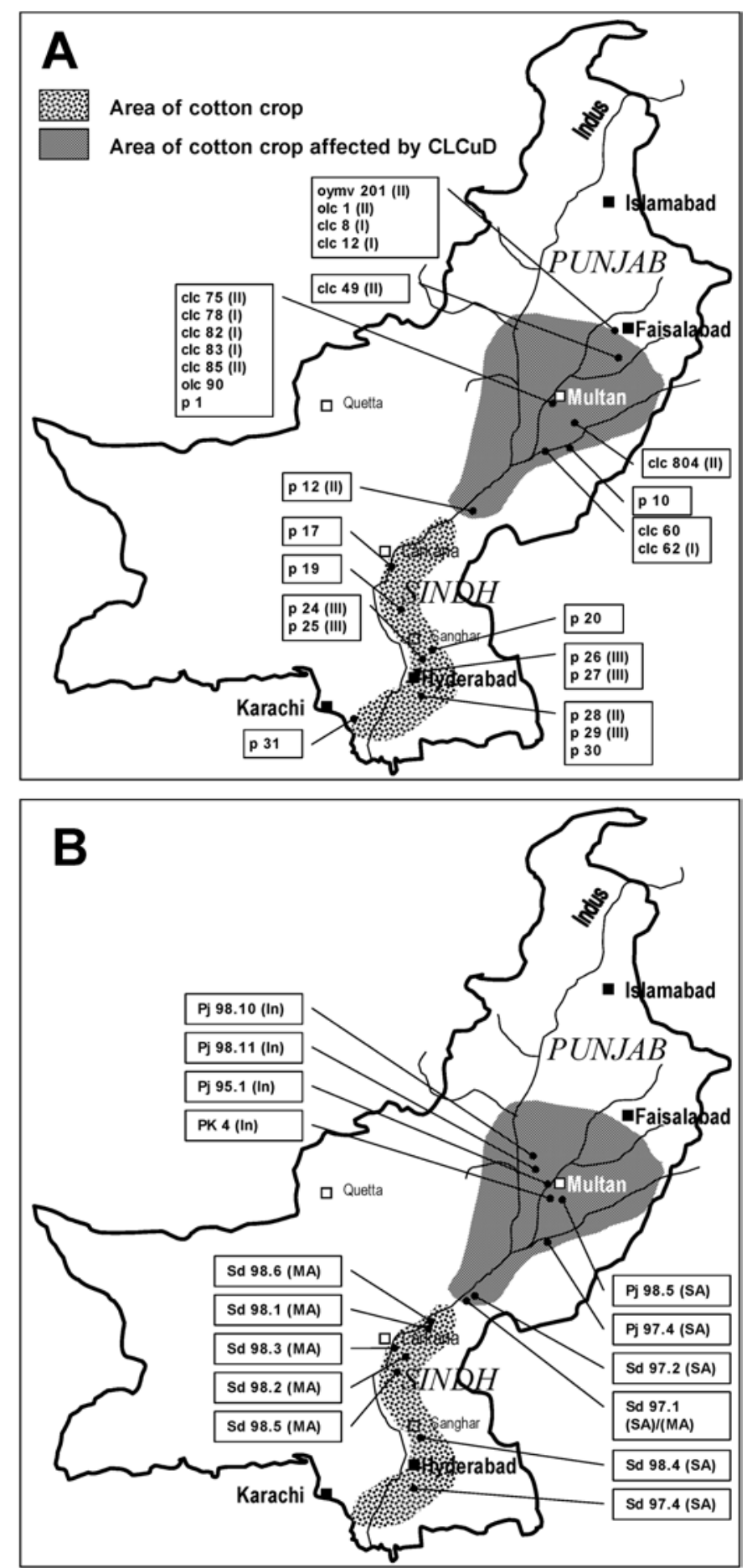

Fig. 1. Map of Pakistan, indicating the sites where A, Begomovirus isolates and $\mathbf{B}$, Bemisia tabaci populations were sampled. Information on the genetic type of the capsid protein of virus isolates (I to III) and on the phylogenetic clade of whiteflies (In: Indian; MA: Mediterranean-African; SA: Southeast Asia) (7) are indicated between parenthesis. The main cotton-growing areas (gray) and the area were cotton leaf curl disease occurs (dark gray) are indicated. 
OPB13, OPC4, OPC10, OPC15, OPO6, and OPO18 (Operon Technologies, Alameda, CA). PCR-amplified fragments were resolved by electrophoresis in $1.4 \%$ agarose gels in Tris-borateEDTA buffer, $\mathrm{pH}$ 7.0. Presence and absence of RAPD bands was used to define haplotypes, and genetic distance between pairs of haplotypes was estimated (42) by $d_{i j}=2 n_{i j} /\left(n_{i}+n_{j}\right)$, where $d_{i j}$ is the genetic distance between haplotypes $i$ and $j, n_{i}$ and $n_{j}$ are the number of RAPD bands in haplotypes $i$ and $j$, respectively, and $n_{i j}$ is the number of bands common to haplotypes $i$ and $j$. Genetic distances were used to estimate within-population diversity. Diversity for population $k, D_{k}$, was computed as $D_{k}=n_{k} /\left(n_{k}-1\right) \Sigma x_{i} x_{j} d_{i j}$, where $n_{k}$ is the number of analyzed individuals, $x_{i}$ and $x_{j}$ are the sample frequency of haplotypes $i$ and $j$, respectively, in population $k$, and $d_{i j}$, is the genetic distance between haplotypes $i$ and $j(41)$.

A second approach, sequencing of mt COI, was done on a set of 25 adult whitefly males randomly sampled from all the local populations in Table 2 . A PCR product of $\approx 700 \mathrm{bp}$ of the $\mathrm{mt}$ COI gene of the samples described in Table 2 was amplified with the primers C1-J-2195 (5'-TTG ATT TTT TGG TCA TCC AGA AGT-3') and L2-N-3014 (5' ${ }^{\prime}$ TCC AAT GCA CTA ATC TGC CAT ATT A-3') (51), according to a previously described protocol (18). The DNA sequence of the amplified fragments was obtained using an ABI Prism 310 automatic sequencer (Applied Biosystems, Foster City, CA). Four sequences were selected from the GenBank (AF342779, AF164667, AF164668, and AF0110708) (7) in order to assign the obtained sequences to known $B$. tabaci clades. Genetic distances among mt COI gene sequences of whiteflies were estimated by Kimura's two-parameter method (32), as explained for Begomovirus DNA sequences. Genetic distances so estimated were used to estimate within-population diversity and the coefficient of genetic differentiation $\left(\mathrm{G}_{\mathrm{ST}}^{\prime}\right)$ (41). Phylogenetic analyses were performed by the neighbor-joining and maximum likelihood methods as described for Begomovirus sequences.

\section{RESULTS}

Genetic structure of the Begomovirus population. The primers used to PCR amplify Begomovirus DNA were designed from the sequence of a single isolate of CLCuMV, but directed the amplification of fragments from other species of $\mathrm{CLCuV}$ and other Begomovirus spp. (50). Thus, isolates from different Begomovirus spp. can be compared, to the extent that their DNA can be amplified with these sets of primers. The analyzed sequence set in this work included all the available sequences of isolates collected from various host plant species from Sindh and a similar number of sequences of isolates from Punjab. The Punjab sequences were randomly sampled within the larger set of sequences available for this province. There were 26 available sequences for the IR and 22 for the CP ORF; 19 of the isolates had both IR and CP sequences (Table 1).

For begomoviruses, it has been shown that sequences within the IR and the CP ORF can be useful markers to analyze diversity (7). Thus, using the IR and CP sequences described above, genetic distances between each pair of isolates were estimated and phylogenetic relatedness was estimated for these two genomic regions. In the case of the IR, all virus isolates clustered into one of two groups, referred to as IR I and IR II (Fig. 2). Isolates in cluster IR I were from malvaceous hosts, whereas most (7/9) isolates in cluster IR II were from nonmalvaceous hosts (Table 1; Fig. 2). Hence, analysis of the IR showed a significant clustering $\left(P<10^{-4}\right.$ in a contingency analysis) of Begomovirus isolates according to the host plant from which it was detected (i.e., from the family Malvaceae or from another host). Sequences in cluster IR I grouped with $\mathrm{CLCuV}$ species from Pakistan (49,50,55) (i.e.,

TABLE 1. Origin of Begomovirus isolates used in this work

\begin{tabular}{|c|c|c|c|c|}
\hline Virus & Place & Year & Host plant (symptom) $^{\mathrm{a}}$ & Accession no. ${ }^{\mathrm{b}}$ \\
\hline \multicolumn{5}{|c|}{ Punjab } \\
\hline oymv 201 & Faisalabad & 1995 & Okra (yellow vein mosaic) & AJ002451 \\
\hline olc 1 & Faisalabad & 1995 & $\overline{\mathrm{Okra}}($ leaf curl $)$ & AJ228575, AJ228585 \\
\hline $\operatorname{clc} 12$ & Faisalabad & 1995 & $\overline{\text { Cotton (leaf curl) }}$ & AJ228576, AJ228586 \\
\hline $\operatorname{clc} 49$ & Sahiwal & 1995 & $\overline{\text { Cotton (leaf curl) }}$ & AJ228577, AJ228590 \\
\hline $\operatorname{clc} 60$ & Bahawalpur & 1995 & Saklai (leaf curl) & AJ228591 \\
\hline $\operatorname{clc} 62$ & Bahawalpur & 1995 & Cotton (leaf curl) & AJ002447 \\
\hline clc 82 & Multan & 1995 & Cotton (leaf curl) & AJ228582, AJ228595 \\
\hline $\operatorname{clc} 83$ & Multan & 1995 & $\overline{\text { Cotton (leaf curl) }}$ & AJ228583, AJ228596 \\
\hline clc 85 & Multan & 1995 & $\overline{\text { Cotton (leaf curl) }}$ & AJ228584, AJ228597 \\
\hline olc 90 & Multan & 1995 & Okra (yellow vein mosaic) & AJ228599 \\
\hline clc 804 & Alabad & 1996 & Cotton (leaf curl) & AJ002452 \\
\hline $\mathrm{p} 1$ & Multan & 1997 & Tomato (yellow leaf curl) & AJ270852 \\
\hline $\mathrm{p} 10$ & Ahmad Pur & 1997 & Cotton (leaf curl) & AJ270853 \\
\hline p 20 & Shahdadpur & 1997 & Goar (yellow mosaic) & AJ270857 \\
\hline p 24 & Mirpur Khas & 1997 & Weed 1 (yellow leaf curl) & AJ245458, AJ270895 \\
\hline p 25 & Mirpur Khas & 1997 & Weed 2 (yellow vein) & AJ245459, AJ270896 \\
\hline p 26 & Hyderabad & 1997 & Hollyhock (leaf curl) & $\begin{array}{l}\text { AJ270860, AJ } 245497 \\
\text { AJ496520 }\end{array}$ \\
\hline p 27 & Hyderabad & 1997 & Tobacco (leaf curl) & AJ270861, AJ245498 \\
\hline p 28 & Tando Muhammad Khan & 1997 & Tomato (yellow leaf curl) & AJ270862, AJ245499 \\
\hline p 29 & Tando Muhammad Khan & 1997 & Bottlegourd (yellow mosaic) & $\mathbf{A J} 270863, A J 245500$ \\
\hline p 30 & Tando Muhammad Khan & 1997 & Watermelon (severe stunt) & AJ245501 \\
\hline p 31 & Karachi & 1997 & China rose (leaf curl) & AJ270864 \\
\hline
\end{tabular}

${ }^{\mathrm{a}}$ Host plants are: Bottlegourd = Luffa cylindrica, China rose $=$ Hibiscus rosa-chinense, Cotton = Gossypium hirsutum, Guar $=$ Cyanopsis tetragonobola, Hollyhock = Althaea rosea, Okra = Abelmoschus sculentus, Saklai $=$ Hibiscus tiliaceus, Tobacco = Nicotiana tabacum, Tomato = Lycopersicon esculentum, Watermelon = Citrullus lanatus. Hosts in the family Malvaceae are underlined.

${ }^{\mathrm{b}}$ Accession numbers for intergenic region sequences are in bold, and those for capsid protein genes are in italics. 
CLCuAV, CLCuKV, and CLCuMV) (data not shown). Comparison of the analyzed sequences with those in the databases showed that the IR of p27 is most related (93\% similarity) to that of Papaya leaf curl virus from India (accession no. Y15934), and

TABLE 2. Origin of Bemisia tabaci populations analyzed in this study

\begin{tabular}{llcl}
\hline Population & Place & Year & Host plant \\
\hline & Punjab & & \\
PK4 & Multan & $<1995$ & Unknown \\
Pj 95. 1 & Multan & 1995 & Cotton \\
Pj 97. 1 & Multan & 1997 & Eggplant \\
Pj 97.2 & Multan & 1997 & Eggplant \\
Pj 97.4 & Ahmad Pur & 1997 & Eggplant \\
Pj 98.5 & Multan & 1998 & Eggplant \\
Pj 98.6 & Multan & 1998 & Eggplant \\
Pj 98.7 & Kloor Kot & 1998 & Mung bean \\
Pj 98. & Nattak & 1998 & Mung bean \\
Pj 98.9 & Kroore & 1998 & Mung bean \\
Pj 98.10 & Fateh Pur & 1998 & Cotton \\
Pj 98.11 & Chak 99 & 1998 & Mung bean \\
& Sindh & & \\
Sd 97.1 & Mirpur Mathelo & 1997 & Hollyhock \\
Sd 97.2 & Ubaro & 1997 & Eggplant \\
Sd 97.3 & Shahdadpur & 1997 & Melon \\
Sd 97.4 & Tando Muhammad Khan & 1997 & Eggplant \\
Sd 98.1 & Khairpur & 1998 & Cotton \\
Sd 98.2 & Kot Digi & 1998 & Cotton \\
Sd 98.3 & Larkana & 1998 & Okra \\
Sd 98.4 & Sanghar & 1998 & Unknown \\
Sd 98.5 & Moro & 1998 & Cotton \\
Sd 98.6 & Sumar Chanar & 1998 & Zucchini squash with \\
& & & silverleaf phenotype \\
\hline
\end{tabular}

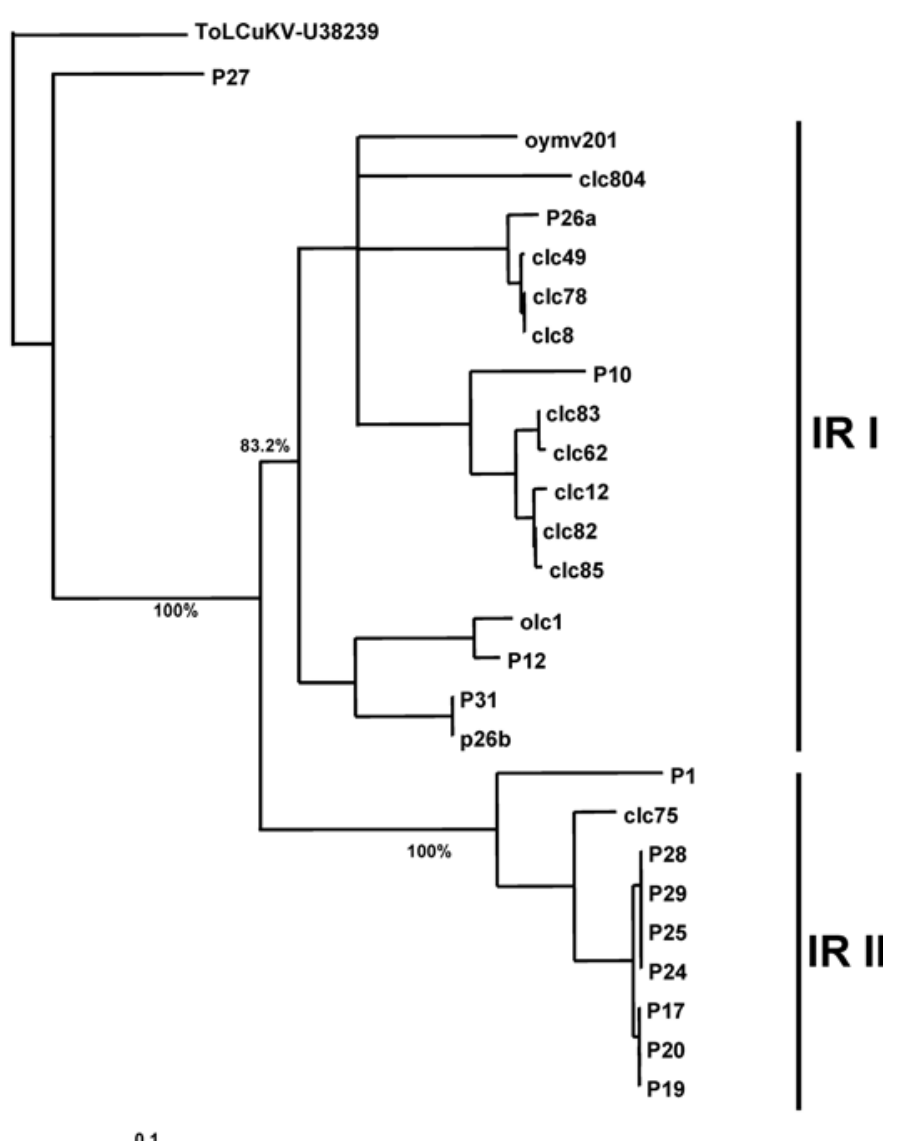

Fig. 2. Phylogenetic tree generated with the nucleotide sequence of the intergenic region (IR) and the neighbor-joining method for 26 Begomovirus isolates from Pakistan. Tomato leaf curl Karnataka virus (U38239) was used as an outgroup. One thousand bootstrap replications were done and all branches below $60 \%$ were collapsed; bootstrap values for the main nodes are indicated. that sequences in cluster IR II are related (up to $98 \%$ similarity) to Tomato leaf curl New Delhi virus (accession no. U15016) (data not shown).

A similar analysis was done with the CP ORF. Analysis of the CP ORF sequences for the 19 isolates for which IR sequences were available showed three significant clusters (Fig. 3). Isolates from malvaceous hosts grouped in clusters CP I and CP II, and those from nonmalvaceous hosts in cluster CP III $(P=0.004$ in a contingency analysis). Sequences from malvaceous hosts in cluster CP I grouped with reference sequences of CLCuMV (e.g., clc62, accession no. AJ002447), whereas some of the sequences of the cluster CP II belonged to CLCuAV and Okra yellow vein mosaic virus (e.g., clc804, accession no. AJ002452, and oymv201, accession no. AJ002451) (17) (Fig. 3). Geographical origin also was a significant factor for clustering $(P=0.004$ in a contingency analysis). Isolates in cluster CP I all were from the Punjab, those in cluster CP III all were from Sindh, and those in cluster CP II were from both regions. Similar results were obtained when the analysis was done with the $22 \mathrm{CP}$ sequences indicated in Table 1 (data not shown).

For both the IR and the $\mathrm{CP}$, the phylogenetic relationships among isolates was the same when analyses were done using the neighbor-joining (Figs. 2 and 3) or the maximum likelihood (data not shown) methods.

Genetic structure of the $B$. tabaci populations. The RAPDPCR reaction produced the amplification of numerous random DNA fragments (Fig. 4) for all the individuals analyzed from all populations. Every individual analyzed was of a different haplo-

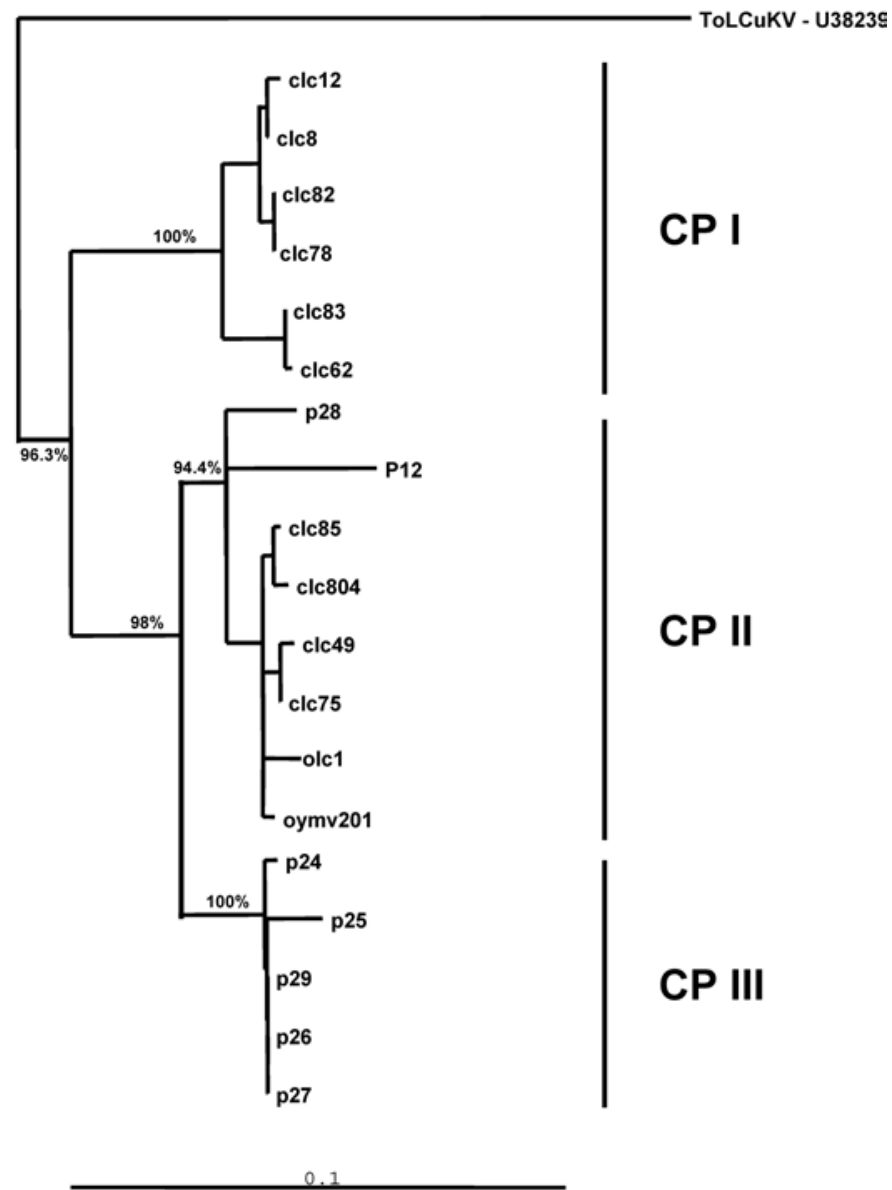

Fig. 3. Phylogenetic tree generated with the nucleotide sequence of the capsid protein $(\mathrm{CP})$ open reading frame and the neighbor-joining method for 19 Begomovirus isolates from Pakistan. Tomato leaf curl Karnataka virus (U38239) was used as an outgroup. One thousand bootstrap replications were done and all branches below 60\% were collapsed; bootstrap values for the main nodes are indicated. 
type, as defined by the presence or absence of the RAPD-PCR polymorphic bands, although some differed by only a few fragments (Fig. 4). Genetic distance between haplotypes was used to estimate within-population diversity. Intrapopulation diversity for all field populations was high, 0.15 to 0.23 (Table 3). Laboratory populations were less diverse. The population diversity estimates for the RAPD-PCR analysis of 24 individuals randomly sampled from all field populations in Table 3 (i.e., those collected in 1997 and 1998) yielded a value of 0.3049 . Hence, the whitefly population from Punjab plus Sindh was not much more diverse than for the most diverse local populations (compare values of 0.30 for the entire population and 0.23 for $\mathrm{Pj} 98.8$ and $\mathrm{Sd} 97.3$ in Table 3). A cluster analysis of the data for each of the nine individual whiteflies from seven of the populations in Table 3 showed three distinct clusters. One cluster contained the reference population of biotype B collected in Spain, Sd 98.2 and Sd 98.6. A second cluster contained populations PK4 and $\mathrm{Pj}$ 95.1. A third cluster contained populations from biotype $\mathrm{K}$ from Pakistan $(2,15)$ and $\mathrm{Pj}$ 98.5. The nine individuals from each population clustered together, with the exception of those of population Sd 98.6. Six individuals from population Sd 98.6 formed a cluster sister to that of population $\mathrm{Sd}$ 98.2, one individual clustered with the nine individuals of population Sd 98.2, and two other formed an independent cluster within the larger one including population B from Spain, Sd 98.2, and Sd 98.6 (data not shown).

B. tabaci population structure also was examined using the $\mathrm{mt}$ $\mathrm{COI}$ gene sequence obtained from 25 whiteflies randomly sampled from the entire set of local populations. Phylogenetic analyses indicated that the Pakistan population of B. tabaci comprises three main genetic types (Fig. 5). Types I and III were found only in the

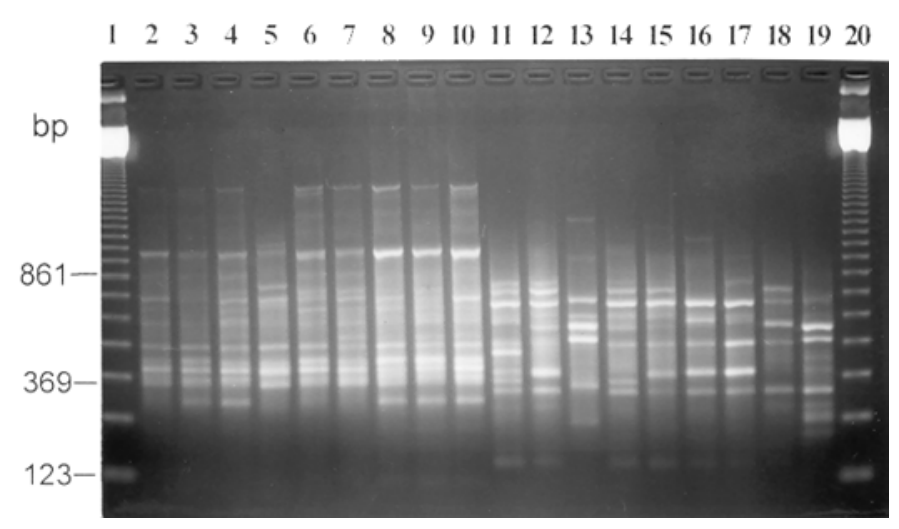

Fig. 4. Random amplified polymorphism DNA-polymerase chain reaction analysis of whiteflies. Results of amplification for primer OPC-4. Lanes 1 and 20: molecular weight marker, 123-bp ladder (Invitrogen, PA); lanes 2 to 10: nine individuals of reference population of biotype K; lanes 11 to 19: nine individuals from population $\mathrm{Pj}$ 95.1.

TABLE 3. Genetic diversity of Bemisia tabaci populations $^{\mathrm{a}}$

\begin{tabular}{lc}
\hline Population & $d_{i j}$ \\
\hline B & 0.06 \\
K & 0.08 \\
PK4 & 0.14 \\
Pj 95.1 & 0.16 \\
Pj 98.5 & 0.18 \\
Pj 98.8 & 0.23 \\
Pj 98.9 & 0.16 \\
Sd 97.1 & 0.13 \\
Sd 97.2 & 0.19 \\
Sd 97.3 & 0.23 \\
Sd 97.4 & 0.22 \\
Sd 98.2 & 0.15 \\
Sd 98.6 & 0.16 \\
\hline
\end{tabular}

a Population diversity was estimated from random amplified polymorphic

DNA data from individual adult insects.
Punjab or Sindh, respectively, whereas type II was found in both the Punjab and Sindh. For some populations, sequences for more than one individual were determined. In most cases, sequences belonged to the same type (i.e., type I for population PK4, type II for $\mathrm{Pj} 98.5$ and $\mathrm{Sd}$ 97.2, and type III for Sd 98.1, Sd 98.2, Sd 98.3, and Sd 98.6), but individuals of different types also could be found within one population (i.e., individuals from population $\mathrm{Sd}$ 97.1 clustered in types II and III).

Some mt COI sequences from the EMBL data bank were included in the analysis. Type I sequences clustered with sequence AF342779 from Nepal, and composed a clade also reported to contain populations from India (7). Type II sequences clustered with sequence AF164668, belonging to the Southeast Asia-Far East clade (7). Finally, type III sequences clustered with sequence AF164667 from Israel (7), which represents the MediterraneanAfrican clade of $B$. tabaci. Because this sequence is of a population previously identified as the B biotype (7) and Sd 98.6, also placed in this group, was collected from squash plants exhibiting silverleaf, phenotype characteristic of B biotype (14), these results suggest that whiteflies in cluster III (Fig. 5) may be the $\mathrm{B}$ biotype. These results are consistent with the detection of $B$. tabaci biotype $\mathrm{B}$ in Pakistan (25). It also is interesting that $\mathrm{Pj}$ 98.5, which was in the same RAPD group as the biotype K con-

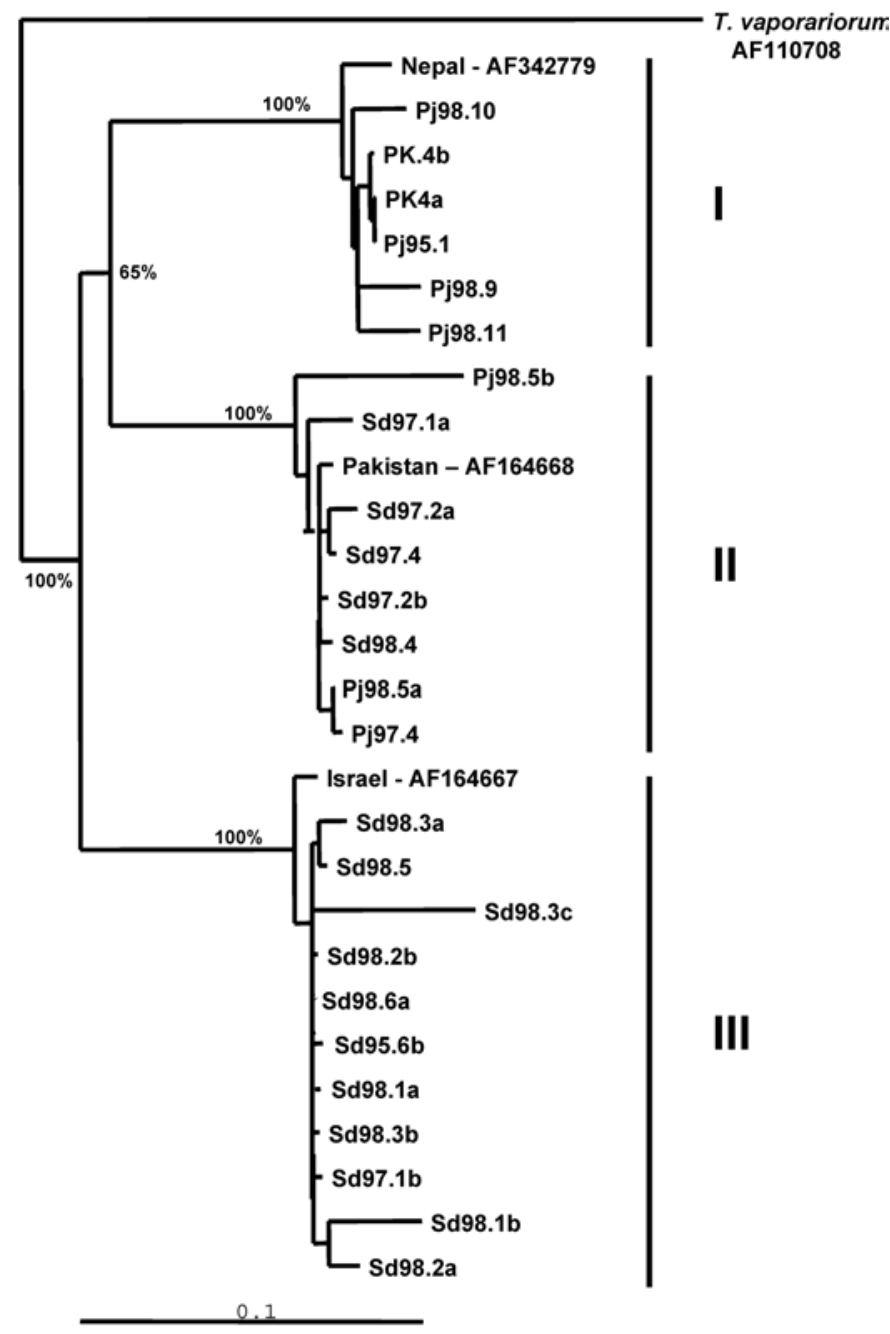

Fig. 5. Phylogenetic tree generated with 25 mitochondrial cytochrome oxidase I gene sequences and the neighbor-joining method for Bemisia tabaci from whiteflies from Pakistan. A sequence of Trialeurodes vaporariorum (AF0110708) (7) was used as outgroup. Reference sequences from the EMBL data bank (AF342779, AF164668, and AF164667) (7) also were included. One thousand bootstrap replications were done and all branches below $60 \%$ were collapsed; bootstrap values for the main nodes are indicated. 
trol, belongs to the Southeast Asian clade. Phylogenetic analysis using maximum likelihood (data not shown) or neighbor-joining (Fig. 5) methods yielded the same results.

Within-population nucleotide diversity for $B$. tabaci was not significantly different for types I, II, and III $(0.0220,0.0259$, and 0.0243 , respectively, $P>0.05$ in a Wilcoxon nonparametric test). Between-population diversity was much higher (0.1306 to 0.1466 ) and yielded a $\mathrm{G}_{\text {ST }}^{\prime}$ (41) of 0.85 , supporting differentiation of $B$. tabaci in Pakistan into at least three types.

\section{DISCUSSION}

Recombination and reassortment seem to have had an important role in the diversification of the family Geminiviridae $(28,45)$. It has been shown experimentally that these mechanisms may account for the emergence of new Begomovirus forms after the introduction of DNA A and DNA B from related but different viruses into a common host $(29,30)$. This likely has occurred also in nature, as shown in a number of instances $(49,50,54,55)$. However, little is known of the factors that drive Begomovirus evolution in nature (i.e., what factors determine that a new genotype increases its frequency in, or is lost from, the virus population). An approach to gain insight into some of these factors is the analysis of the genetic structure of the virus population and its relationship with the environment. Major environmental factors include the host plant species and the whitefly vector, because they condition the viral distribution in crop ecosystems. Begomoviruses are transmitted by $B$. tabaci, a species complex (10) of temperate and tropical distribution. Changes in the number, distribution, and genetic structure of $B$. tabaci have been suggested to contribute to the emergence of new begomoviral diseases $(7,8,33-35,47)$. The host often is considered in analyses of plant virus population structure (19), whereas joint analyses of the population structure of both virus and vector are less frequent (35).

We report here a parallel analysis of the genetic structure of begomoviruses and the whitefly vector from cotton-growing areas in Pakistan, including the provinces of the Punjab, where CLCuD is rampant, and Sindh, where CLCuD has only recently been reported in the northern part of the province $(1,5,31)$. The virus isolates described in this work, and others collected in the same cotton-growing areas of Pakistan, have been reported previously $(49,50,55)$. In these previous reports the extent of genetic diversity $(49,55)$ and the role of recombination in the evolution of CLCuVlike begomoviruses $(49,50)$ was analyzed. The set of isolates considered here has not been jointly analyzed before, nor has the role of the host plant and insect vector in their evolution been investigated.

Mixed infections between different Begomovirus spp. and strains, and recombinants among them, have been shown to be frequent $(49,50,55)$. Hence, it should not be unexpected that the genetic structure of the virus population examined in the present study differed according to the genomic region considered. For the IR, isolates clustered according to the host plant family (i.e., isolates collected from plants in the family Malvaceae [mostly cotton] or from other dicotyledon families). The IR has a role in mediating DNA replication by binding with the virus-encoded protein Rep. Rep interacts with the $5^{\prime}$ half of the IR $(23,26)$, and it has been suggested that host plant components may be a factor in the evolution of the IR (28). Our results are consistent with this hypothesis, but definitive experimental evidence needs to be obtained.

It also has been proposed that the main selection factor for geminivirus $\mathrm{CP}$ is the interaction with the insect vector (28). Our phylogenetic analysis of the CP ORF revealed three clusters correlated with geographical regions, comprising types found only in Punjab or in Sindh, and another type found in both regions. It is noteworthy that sequence analysis of the $B$. tabaci population also revealed three clusters with the same geographical distribution.
The similar genetic structure for the viral $\mathrm{CP}$ and the vector $\mathrm{mt}$ COI genes is suggestive of a relationship between both.

The population of $B$. tabaci in Pakistan is highly diverse. Three genetic types, representing the Indian, Southeast Asian, and Mediterranean-African phylogenetic clades (7), were identified in the analyzed region. The Indian and Southeast Asian clade types were detected in Punjab, and the Southeast Asian and Mediterranean African clade types in Sindh. It is possible that haplotypes belonging to the two clades present in one region are found together in the same population, as shown for population $\mathrm{Sd} 97.1$ (Fig. 5). This would result in high genetic diversity at the local population scale, as shown in Table 3.

The presence in Pakistan of at least three genetic types of $B$. tabaci was shown in previous reports $(7,25)$. However, results presented here from a larger sample size provide a view of the geographical distribution of these types. It is noteworthy that the Indian clade type appears predominant in the Punjab, and the Mediterranean African clade type in the Sindh; however, the reason for this is unknown at present, because no obvious geographical barrier occurs in the Indus Valley. The displacement of biotypes of $B$. tabaci by another in a region has been reported $(3,15,35,39)$. However, the dynamics of this phenomenon may be complex, and different factors such as biological fitness in some hosts, resistance to insecticides, and susceptibility to parasitoids $(10,14,15)$ can influence the distribution of B. tabaci genotypes.

Previous detailed analyses of the population structure of $B$. tabaci in a region have revealed limited diversity, with one or two dominant types prevailing $(13,15,35,39)$. The higher genetic diversity of the population from Punjab and Sindh is compatible with the origin of $B$. tabaci in the Indian subcontinent, which also has been proposed based on the high diversity of parasitoids for this region $(10,21,37)$. It is interesting to note that several sequences in cluster III (Fig. 5), including one from Sd 98.6 that was collected from squash with silverleaf symptoms (14), were highly similar (above $97 \%$ nucleotide sequence identity) to a sequence for the B biotype from Israel (AF164667) (7). This indicates that the B biotype was present in Pakistan at the time these samples were collected and suggests that it may be widespread in Sindh (Table 2; Fig. 1B).

The emergence of CLCuD was associated with the widespread use of a highly susceptible cotton cultivar, S129 $(5,43)$, and it has been speculated that new begomoviruses of recombinant origin could have an increased fitness on this cultivar (55). CLCuD occurs where $B$. tabaci type I (the Indian phylogenetic clade type) is found. Thus, the distribution of CLCuD may have been influenced by the distribution of the Indian genotype of B. tabaci. It has been hypothesized that geographical distribution of virus genotypes and vector genotypes is highly correlated (7). Our data agree with this hypothesis for the cotton-growing area of Pakistan, because similar genetic structures were revealed for the viral $\mathrm{CP}$ and the $B$. tabaci $\mathrm{mt}$ COI genes. This may suggest that the insect vector is an important factor in virus evolution, an aspect that remains to be experimentally explored.

\section{ACKNOWLEDGMENTS}

This work was supported in part by Contract CI $1 *$-CT94-0052 of the EU and project AGC2001-1857-C04 of MCYT from Spain. B. Simón received a fellowship (ref. PN98-44850256) of Programa Nacional de Formación de Personal Investigador, Ministerio de Educación y Cultura, Spain. We thank J. Galián (University of Murcia) for his help with DNA sequencing.

\section{LITERATURE CITED}

1. Ali, M., Ahmad, Z., Tanveer, M., and Mahmood, T. 1995. Cotton leaf curl virus in the Punjab: Current situation and review of work. Central Cotton Research Institute/Ministry of Food, Agriculture and Livestock, Government of Pakistan/Asian Development Bank, Multan, Pakistan. 
2. Bedford, I. D., Briddon, R. W., Brown, J. K., Rosell, R. C., and Markham, P. G. 1994. Geminivirus transmission and biological characterisation of Bemisia tabaci (Gennadius) biotypes from different geographic regions. Ann. Appl. Biol. 125:311-325.

3. Bird, J., and Brown, J. K. 1998. Displacement of the Sida race of Bemisia tabaci by the B biotype of B. tabaci complex in Puerto Rico. Abstracts of the 2nd International Workshop on Bemisia and Geminiviral Diseases, San Juan, Puerto Rico.

4. Briddon, R. W., Mansoor, S., Bedford, I. D., Pinner, M. S., Saunders, K., Stanley, J., Zafar, Y., Malik, K. A., and Markham, P. G. 2001. Identification of DNA component required for induction of cotton leaf curl disease. Virology 285:234-243.

5. Briddon, R. W., and Markham, P. G. 2000. Cotton leaf curl virus disease. Virus Res. 71:151-159.

6. Brown, J. K. 1994. Current status of Bemisia tabaci as a plant pest and virus vector in agroecosystems worldwide. FAO Plant Prot. Bull. 42:332.

7. Brown, J. K. 2000. Molecular markers for the identification and global tracking of whitefly vector-Begomovirus complexes. Virus Res. 71:233260.

8. Brown, J. K., and Bird, J. 1992. Whitefly-transmitted geminiviruses and associated disorders in the Americas and the Caribbean Basin. Plant Dis. 76:220-225.

9. Brown, J. K., Coats, S. A., Bedford, I. D., Markham, P. G., Bird, J., and Frohlich, D. R. 1995. Characterization and distribution of esterase electromorphs in the whitefly, Bemisia tabaci (Genn.) (Homoptera: Aleyrodidae). Biochem. Genet. 33:205-214.

10. Brown, J. K., Frolich, D. R., and Rosell, R. C. 1995. The sweetpotato or silverleaf whiteflies: Biotypes of Bemisia tabaci or a species complex? Ann. Rev. Entomol. 40:511-534.

11. Cenis, J. L., Pérez, P., and Fereres, A. 1993. Identification of aphid (Homoptera: Aphididae) species and clones by random amplified polymorphic DNA. Ann. Entomol. Soc. Am. 86:545-550.

12. Cervera, M. T., Cabezas, J. A., Simón, B., Martínez-Zapater, J. M., Beitia, F., and Cenis, J. L. 2000. Genetic relationships among biotypes of Bemisia tabaci (Hemiptera: Aleyrodidae) based on AFLP analysis. Bull. Entomol. Res. 90:391-396.

13. Chermitti, B., Brahams, M., Cenis, J. L., Alonso, C., and Beitia, F. 1997. Sur la présence en Tunisie des biotypes "B" et "non B" de Bemisia tabaci (Homoptera, Aleyrodidae) et de leurs parasitoïdes associés. IOBC/WPRS Bull. 20:108-113.

14. Costa, H. S., and Brown, J. K. 1991. Variation in biological characteristics and esterase patterns among populations of Bemisia tabaci Genn. and the association of one population with silverleaf symptom induction. Entomol. Exp. Appl. 61:211-219.

15. Costa, H. S., Brown, J. K., Sivasupramanian, S., and Bird, J. 1993. Regional distribution, insecticide resistance and reciprocal crosses between the A and B biotypes of Bemisia tabaci. Insect Sci. Appl. 14: 255-266.

16. De Barro, P. J., Driver, F., Trueman, J. W. H., and Curran, J. 2000. Phylogenetic relationship of world populations of Bemisia tabaci (Gennadius) using ribosomal ITS1. Mol. Phylogenet. Evol. 16:29-36.

17. Fauquet, C. M., Bisaro, D. M., Briddon, R. W., Brown, J. K., Harrison, B. H., Ribicki, E. P., Stenger, D. C., and Stanley, J. 2003. Revision of taxonomic criteria for species demarcation in the family Geminiviridae, and an updated list of begomovirus species. Arch. Virol. 148:405-421.

18. Frohlich, D. R., Torres-Jerez, I., Bedford, I. D., Markham, P. G., and Brown, J. K. 1999. A phylogeographic analysis of the Bemisia tabaci species complex based on mitochondrial DNA markers. Mol. Ecol. 8:1593-1602.

19. García-Arenal, F., Fraile, A., and Malpica, J. M. 2001. Variability and genetic structure of plant virus populations. Annu. Rev. Phytopathol. 39:157-186.

20. Gawel, N. J., and Bartlett, A. C. 1993. Characterization of differences between whiteflies using RAPD-PCR. Insect Mol. Biol. 2:33-38.

21. Gill, R. J. 1992. A review of the sweetpotato whitefly in Southern California. Pan-Pac. Entomol. 68:144-152.

22. Guirao, P., Beitia, F., and Cenis, J. L. 1997. Biotype determination of Spanish populations of Bemisia tabaci (Hemiptera:Aleyrodidae). Bull. Entomol. Res. 87:587-593.

23. Gutierrez, C. 2000. DNA replication and cell cycle in plants: learning from geminiviruses. EMBO J. 19:792-799.

24. Hameed, S., Khalid, S., Ehsan-ul-Haq, S., and Hashmi, A. A. 1994. Cotton leaf curl disease in Pakistan caused by a whitefly-transmitted geminivirus. Plant Dis. 78:529.

25. Hameed, S., Khalid, S., and Saqlan Naqvi, S. M. 1996. Occurrence of Bbiotype of Bemisia tabaci in Pakistan. Pages 81-85 in: British Crop Protection Council.
26. Hanley-Bowdoin, L., Settlage, S. B., Orozco, B. M., Nagar, S., and Robertson, D. 1999. Geminiviruses: Models for plant DNA replication, transcription and cell cycle regulation. Crit. Rev. Plant Sci. 18:71-106.

27. Harrison, B. D., Liu, Y. L., Khalid, S., Hameed, S., Otim-Nape, G. W., and Robinson, D. J. 1997. Detection and relationships of cotton leaf curl virus and allied whitefly-transmitted geminiviruses occurring in Pakistan. Ann. Appl. Biol. 130:61-75.

28. Harrison, B. D., and Robinson, D. J. 1999. Natural genomic and antigenic variation in whitefly-transmitted geminiviruses (begomoviruses). Annu. Rev. Phytopathol. 37:369-398.

29. Hou, Y. M., and Gilbertson, R. L. 1996. Increased pathogenicity in a pseudorecombinant bipartite geminivirus correlates with intermolecular recombination. J. Virol. 70:5430-5436.

30. Hou, Y. M., Paplomatas, E. J., and Gilbertson, R. L. 1998. Host adaptation and replication properties of two bipartite geminiviruses and their pseudorecombinants. Mol. Plant-Microbe Interact. 11:208-217.

31. Khalid, S., Soomro, M. H., and Ahmad, I. 1997. Occurrence of cotton leaf curl virus (CLCuV) in Sindh. Pak. J. Bot. 29:173-174.

32. Kimura, M. 1980. A simple method for estimating evolutionary rates of base substitutions through comparative studies of nucleotide sequences. J. Mol. Evol. 16:111-120.

33. Kirk, A. A., Lacey, L. A., Brown, J. K., Ciomperlik, M. A., Goolsby, J. A., Vacek, D. C., Wendel, L. E., and Napompeth, B. 2000. Variability within the Bemisia tabaci complex (Homoptera:Aleyrodidae) and its natural enemies: Successful biological control of type B in the USA. Bull. Entomol. Res. 90:317-327.

34. Legg, J. P. 1999. Emergence, spread and strategies for controlling the pandemic of cassava mosaic virus disease in East and Central Africa. Crop Prot. 18:627-637.

35. Legg, J. P., French, R., Rogan, D., Okao-Okuja, G., and Brown, J. K. 2002. A distinct Bemisia tabaci (Gennadius) (Hemiptera: Sternorrhynca: Aleyrodidae) genotype cluster is associated with the epidemic of severe cassava mosaic virus disease in Uganda. Mol. Ecol. 11:12191229.

36. Liu, Y., Robinson, D. J., and Harrison, B. D. 1998. Defective forms of cotton leaf curl virus DNA-A that have different combinations of sequence deletion, duplication, inversion and rearrangement. J. Gen. Virol. 79:1501-1508.

37. López-Avila, A. 1996. Taxonomy and Biology. Pages 3-11 in: Bemisia tabaci: A Literature Survey on the Cotton Whitefly with Annotated Bibliography. M. J. W. Cock, ed. CAB International Institute for Biological Control, Ascot, Berks, UK.

38. Moffat, A. M. 1999. Geminiviruses emerge as serious crop threat. Science 286:1835

39. Moya, A., Guirao, P., Cifuentes, D., Beitia, F., and Cenis, J. L. 2000. Genetic diversity of Iberian populations of Bemisia tabaci (Hemiptera: Aleyrodidae) based on RAPDs. Mol. Ecol. 10:891-898.

40. Nadeem, A. 1995. Molecular characterization of two cotton geminiviruses. Ph.D. diss. University of Arizona, Tucson.

41. Nei, M. 1987. Molecular Evolutionary Genetics. Columbia University Press, New York.

42. Nei, M., and Li, W. H. 1979. Mathematical model for studying genetic variation in terms of restriction endonucleases. Proc. Natl. Acad. Sci. USA 76:5269-5273.

43. Nelson, M. R., Orum, T. V., Jaime-García, R., and Nadeem, A. 1999. Applications of geographic information systems and geostatistics in plant disease epidemiology and management. Plant Dis. 83:308-319.

44. Noris, E., Hidalgo, E., Accotto, G. P., and Moriones, E. 1994. High similarity among the Tomato yellow leaf curl virus isolates from the West Mediterranean Basin: The nucleotide sequence of an infectious clone from Spain. Arch. Virol. 135:165-170.

45. Padidam, M., Sawyer, S., and Fauquet, C. M. 1999. Possible emergence of new geminiviruses by frequent recombination. Virology 265:218-225.

46. Perring, T. M. 2001. The Bemisia tabaci species complex. Crop Prot. 20:725-737.

47. Polston, J. E., and Anderson, P. K. 1997. Emergence of whitefly-transmitted geminiviruses in tomato in the Western Hemisphere. Plant Dis. 81:1358-1369.

48. Sánchez-Campos, S., Navas-Castillo, J., Camero, R., Soria, C., Díaz, J. A., and Moriones, E. 1999. Displacement of Tomato yellow leaf curl virus (TYLCV)-Sr by TYLCV-Is in tomato epidemics in Spain. Phytopathology 89:1038-1043.

49. Sanz, A. I., Fraile, A., Gallego, J. M., Malpica, J. M., and GarcíaArenal, F. 1999. Genetic variability of natural populations of cotton leaf curl geminivirus, a single-stranded DNA virus. J. Mol. Evol. 49:672681.

50. Sanz, A. I., Fraile, A., García-Arenal, F., Zhou, X., Robinson, D. J., Khalid, S., Butt, T., and Harrison, B. D. 2000. Multiple infection, 
recombination and genome relationships among begomovirus isolates in cotton and other plants in Pakistan. J. Gen. Virol. 81:18391849.

51. Simon, C., Frati, F., Beckembach, A., Crespi, B, Liu, H., and Flook, P. 1994. Evolution, weighting and phylogenetic utility of mitochondrial gene sequences and a compilation of conserved polymerase chain reaction primers. Ann. Entomol. Soc. Am. 87:651-701.

52. Thompson, J. D., Higgins, D. G., and Gibson, T. J. 1994. CLUSTAL W: Improving the sensitivity of progressive multiple sequence alignment through sequence weighting, position of specific gap penalties and weight matrix choice. Nucleic Acids Res. 22:4673-4680.
53. Umaharan, P., Padidam, M., Phelps, R. H., Beachy, R., and Fauquet, C. M. 1998. Distribution and diversity of geminiviruses in Trinidad and Tobago. Phytopathology 88:1262-1268.

54. Zhou, X., Liu, Y., Calvert, L., Muñoz, C., Otim-Nape, G. W., Robinson, D. J., and Harrison, B. D. 1997. Evidence that DNA-A of a geminivirus associated with severe cassava mosaic disease in Uganda has arisen by interspecific recombination. J. Gen. Virol. 78:2101-2111.

55. Zhou, X., Liu, Y., Robinson, D. J., and Harrison, B. D. 1998. Four DNAA variants among Pakistani isolates of Cotton leaf curl virus and their affinities to DNA-A of geminivirus isolates from okra. J. Gen. Virol. 79:915-923. 